\title{
Critical care medicine in Taiwan from 1997 to 2013 under National Health Insurance
}

\author{
Chih-Cheng Lai ${ }^{1 \#}$, Chung-Han $\mathrm{Ho}^{2,3 \#}$, Chia-Li Chang ${ }^{2}$, Chin-Ming Chen ${ }^{4,5}$, Shyh-Ren Chiang ${ }^{5,6}$, Chien- \\ Ming Chao ${ }^{1}$, Jhi-Joung Wang ${ }^{2}$, Kuo-Chen Cheng, ${ }^{6,7}$
}

${ }^{1}$ Department of Intensive Care Medicine, Chi Mei Medical Center, Liouying; ${ }^{2}$ Departments of Medical Research, Chi Mei Medical Center, Tainan; ${ }^{3}$ Department of Hospital and Health Care Administration, Chia Nan University of Pharmacy \& Science, Tainan; ${ }^{4}$ Departments of Intensive Care Medicine, Chi Mei Medical Center, Tainan; ${ }^{5}$ Chia Nan University of Pharmacy \& Science, Tainan; ${ }^{6}$ Departments of Internal Medicine, Chi Mei Medical Center, Tainan; ${ }^{7}$ Department of Safety Health and Environmental Engineering, Chung Hwa University of Medical Technology, Tainan Contributions: (I) Conception and design: CC Lai, CH Ho, KC Cheng; (II) Administrative support: JJ Wang; (III) Provision of study materials or patients: JJ Wang, KC Cheng; (IV) Collection and assembly of data: CH Ho, CL Chang; (V) Data analysis and interpretation: CC Lai, CM Chen, SR Chiang, CM Chao, KC Cheng; (VI) Manuscript writing: All authors; (VII) Final approval of manuscript: All authors.

\#These authors contributed equally to this work.

Correspondence to: Kuo-Chen Cheng, MD. Department of Internal Medicine, Chi Mei Medical Center, 901 Zhonghua Road, Yongkang District, Tainan City 71044. Email: kcg.cheng@gmail.com.

Background: Monitoring of trends in the use of the intensive care unit (ICU) and the outcomes of ICU patients is essential for the assessment of the effective use of ICU. This study aims to investigate the incidence and outcome of critical care admissions in Taiwan from 1997 to 2013.

Methods: Patients >18 years who had ICU admission between January 1997 and December 2013 were identified from the National Health Insurance Research Database in Taiwan. The main outcomes including ICU mortality and ICU length of stay (LOS) were measured.

Results: A total of 3,451,157 patients with ICU admission were identified during the study period. The mean ICU LOS was $5.9 \pm 9.0$ days and the overall ICU-mortality rate was $19.8 \%$. The mean age of the patients was 65.4 years old, $58.0 \%$ were elderly ( $\geq 65$ years old), $61.1 \%$ were male. Annual incidence of ICU admissions increased from 115,754 in 1997 (age-adjusted incidence: 1,130/100,000 population) to 244,820 in 2013 (incidence: 1,483/100,000 population) $(\mathrm{P}<0.0001)$. The admission rate was highest for patients 75-104 years old (8,074 per 100,000 population), and lowest for those 18-44 years old (298 per 100,000 population). Among ICU admission patients, the percentage of patients $\geq 75$ years old significantly increased from $25.2 \%$ in 1997 to $38.3 \%$ in 2013 ( $\mathrm{P}<0.0001$ ). ICU LOS remained stable during the study period, but the annual mortality rate significantly decreased from $23.0 \%$ in 1997 to $16.3 \%$ in 2013 .

Conclusions: ICU admissions significantly increased from 1997 to 2013, especially for elderly patients, in contrast, the mortality rate of ICU patients significantly declined with time. In addition, the ICU LOS did not change during the study period.

Keywords: Critical care; intensive care unit (ICU); mortality; utilization

Submitted Jan 12, 2018. Accepted for publication Jul 24, 2018.

doi: $10.21037 /$ jtd.2018.07.131

View this article at: http://dx.doi.org/10.21037/jtd.2018.07.131

\section{Introduction}

The intensive care unit (ICU) is one important component of acute care. Good outcomes rely on a chain of providers and treatment locations (1-5). In the USA, the annual cost of intensive medicine significantly increased $(92.2 \%$; \$56-108 billion) between 2000 and 2010, and the cost of critical care medicine rose by $32.1 \%$ from $0.54 \%$ of the 
gross domestic product to $0.72 \%$ (1). In addition to the increasing ICU use, mortality and length of stay (LOS) of ICU patients are important quality indicators, but these indicators of care quality remain controversial (6-9). Most studies $(1,10-15)$ on these ICU topics were conducted in western countries, and studies on the ICU in Asia are scant or out of date $(16,17)$. Furthermore, most of those studies were short-term cross-sectional analyses $(15,18)$, and only a few were long-term $(11,19)$. Most important, however, is that the availability and use of critical care service varies in different healthcare systems in different countries (12). In 1995, Taiwan's National Health Insurance (NHI) program was implemented. It now covers over 99\% of Taiwan's population. Since the introduction of this program, the huge barrier between medical service and patients has been removed, and most the utilization of healthcare services, e.g., outpatient visits to physicians, hospital admissions, ICU admissions, etc., have significantly increased (20,21).

The NHI Research Database (NHIRD), is a running record of encrypted NHI claims information about: outpatient visits, diagnoses, hospital admissions, prescriptions, interventional procedures, medical institutions that provided clinical services, outcomes at hospital discharge, and medical costs incurred. Taking the advantage of this comprehensive database, we can assess the epidemiologic trends of ICU uses of Taiwan adult population with time. In this study, we used the NHIRD to realize the incidence and outcome of critical care admissions in Taiwan from 1997 to 2013.

\section{Methods}

\section{Data source}

Our data source was NHIRD. The NHI currently enrolls more than 23 million of the country's legal residents with 99.6\% coverage (22). The NHIRD provides detailed healthcare services information. The database contains data including all patients' medical care, diagnosis, surgery, medications from 1997 to 2013. The Chi Mei Medical Center Institutional Review Board approved the study and specifically waived informed consent.

\section{Patient selection and definition}

The records of adult patients ( $\geq 18$ years old) who had been admitted to the ICU between January 1, 1997 and December 31, 2013, were retrospectively reviewed.
The record of ICU admission was based on the medical expenditure claim applications. The detail medical expenditure applications of ICU were defined by inpatient orders numbers $(02011 \mathrm{~K}, 02012 \mathrm{~A}, 02013 \mathrm{~B}, 03010 \mathrm{E}$, 03010K, 03011A, 03011F, 03012B, 03012G, 03013B, 03013H, 03047E, 03048F, 03049G, 03050H) according to the guideline of NHI. Patient's age and gender were recorded. ICU mortality and LOS were the outcomes of interest.

\section{Statistical analysis}

The categorical variables-age-group, gender, and mortality-are presented as frequencies and percentages. The continuous variables - age, and length of ICU stayare presented as means \pm standard deviation (SD) and medians with an interquartile range. The crude ICU admission rate for each year was defined as the number of ICU admissions dividing by the total population. The Poisson regression was used to estimate age-adjusted ICU admission rate and age-adjusted ICU mortality rate. The trend tests of ICU admission rate, age admitted to ICU, length of ICU stay, and ICU mortality rates were analyzed by linear regression for the years 1997 to 2013. SAS 9.4 for Windows (SAS Institute, Cary, NC, USA) was used for all analyses.

\section{Results}

\section{Demographic characteristics}

ICUs in Taiwan admitted 3,451,157 patients between January 1, 1997, and December 31, 2013. The mean age of the patients was 65.4 years old, $58.0 \%$ were elderly ( $\geq 65$ years old), $61.1 \%$ were male. The mean LOS in the ICU was 5.9 \pm 9.0 days, and 681,706 (19.8\%) patients died in the ICU (Table 1).

\section{ICU admission trend}

During the study period, the annual ICU admissions more than doubled from 115,754 in 1997 to 244,820 in $2013(\mathrm{P}<0.0001)$, and the crude overall ICU admission rate was 1,149 per 100,000 population. The annual ageadjusted ICU admission rate significantly increased from 1,130 per 100,000 population in 1997 to 1,483 in $2013(\mathrm{P}<0.0001)$ (Figure 1). In the meanwhile, the number of ICU beds also increased from 4,573 
Table 1 Characteristics of ICU patients ( $n=3,451,157$ admissions)

\begin{tabular}{lc}
\hline Characteristics & Value \\
\hline Age (years), mean \pm SD & $65.4 \pm 17.6$ \\
$18-44$ & $407,629(14.7)$ \\
$45-54$ & $532,666(15.4)$ \\
$55-64$ & $770,101(22.3)$ \\
$65-74$ & $1,231,238(35.7)$ \\
$\geq 75$ & \\
Gender, $n$ (\%) & $1,343,833(38.9)$ \\
Female & $2,107,324(61.1)$ \\
Male & \\
Type of hospital, $n$ (\%) & $1,274,564(36.9)$ \\
Medical center & $1,613,655(46.8)$ \\
Regional hospital & $562,938(16.3)$ \\
District hospital & \\
ICU length of stay (days) & $581,706(19.8)$ \\
Mean \pm SD & $5.9 \pm 9.0$ \\
Median [IQR] & 3 (CU mortality, $\mathrm{n}(\%)$ \\
\hline
\end{tabular}

ICU, intensive care unit; IQR, interquartile range; SD, standard deviation.

in 1997 to 7,074 in $2013(\mathrm{P}<0.0001)$ (Figure 1). The admission rate was highest for patients $\geq 75$ years old (8,074 per 100,000 population), and lowest for those $18-44$ years old (298 per 100,000 population). For patients 18-44 years old, $45-54$ years old, and $\geq 75$ years old, the ICU admission rates significantly increased with time (all $\mathrm{P}<0.001)$ (Table 2). Among general populations, the percentage of patients $\geq 75$ years old only increased from $3.6 \%$ in 1997 to $6.2 \%$ in $2013(\mathrm{P}<0.0001)$. Among ICU admission patients, after adjusting the factor of age, the percentage of patients $\geq 75$ years old significantly increased from $25.2 \%$ in 1997 to $38.3 \%$ in $2013(\mathrm{P}<0.0001)$ (Figure 2).

\section{ICU LOS trend}

The ICU LOS remained stable with time: mean duration $=5.4$ days in 1997, and =5.6 days in 2013 (Figure 3); it was longest for patients $\geq 75$ years old and shortest for patients 18-44 years old.

\section{Mortality trends}

The number of deaths significantly increased from 26,566 in 1997 to 40,014 in $2013(\mathrm{P}<0.0001)$. The annual mortality rate decreased from $23.0 \%$ in 1997 to $16.3 \%$ in 2013 $(\mathrm{P}<0.0001)$ (Figure 4). Patients $\geq 75$ years old had the highest mortality rate, but it decreased from $32.9 \%$ in 1997 to $22.2 \%$ in $2013(\mathrm{P}<0.0001)$. Mortality rates also significantly decreased in the other age subgroups $(\mathrm{P}<0.0001)$ (Figure 5). The annual mortality rates significantly decreased for both genders from 1997 to 2013 (both $\mathrm{P}<0.0001$ ).

\section{Discussion}

This large national study is a population-based investigation of secular trends of ICU admission and ICU patient outcomes in Taiwan between 1997 and 2013. We found that adult ICU admissions significantly increased, and that the largest increase was for patient $\geq 75$ years old. The mechanism of increasing admission, especially for the elderly patients can be only partly attributed to the changing population in Taiwan. Although Taiwan has a relatively young population $[11.5 \%$ are older than 65 years, compared to $16.5 \%$ for Organization for Economic Cooperation and Development (OECD) countries on average], but also has low fertility rates, resulting in a relatively accelerated aging of the population $(23,24)$. In this study, the percentage of patient $\geq 75$ years old among general populations only increased from 3.6\% in 1997 to $6.2 \%$ in 2013 . But the percentage of patient $\geq 75$ years old among ICU admission patients significantly increased from $25.2 \%$ in 1997 to $38.3 \%$ in 2013 . Therefore, the patients $\geq 75$ years old may carry the higher risk of ICU admission than the other age group. In this study, the trend in ICU admission significantly increases from 1997 to 2003 and seems to be flattening and even downward since 2009 (Figure 1). It is possible due to the change of NHI expenditure and policy. For the expenditure issue, Taiwan's NHI had annual growth in expenditures that outstripped revenues through 2008. Because the government needs to maintain NHI for long time, Taiwan had second generation (G2)-NHI reform in 2013. Therefore, one could speculate that this may have been related to constrain spending, and possibly, ICU utilization. Although the payroll premium changed in 2010 from $4.55 \%$ to $5.17 \%$ of income, this did not translate into an NHI surplus until 2013-so the effect of the budget shift would not have been felt until even after 2013. For the change of NHI policy, in the first-half 


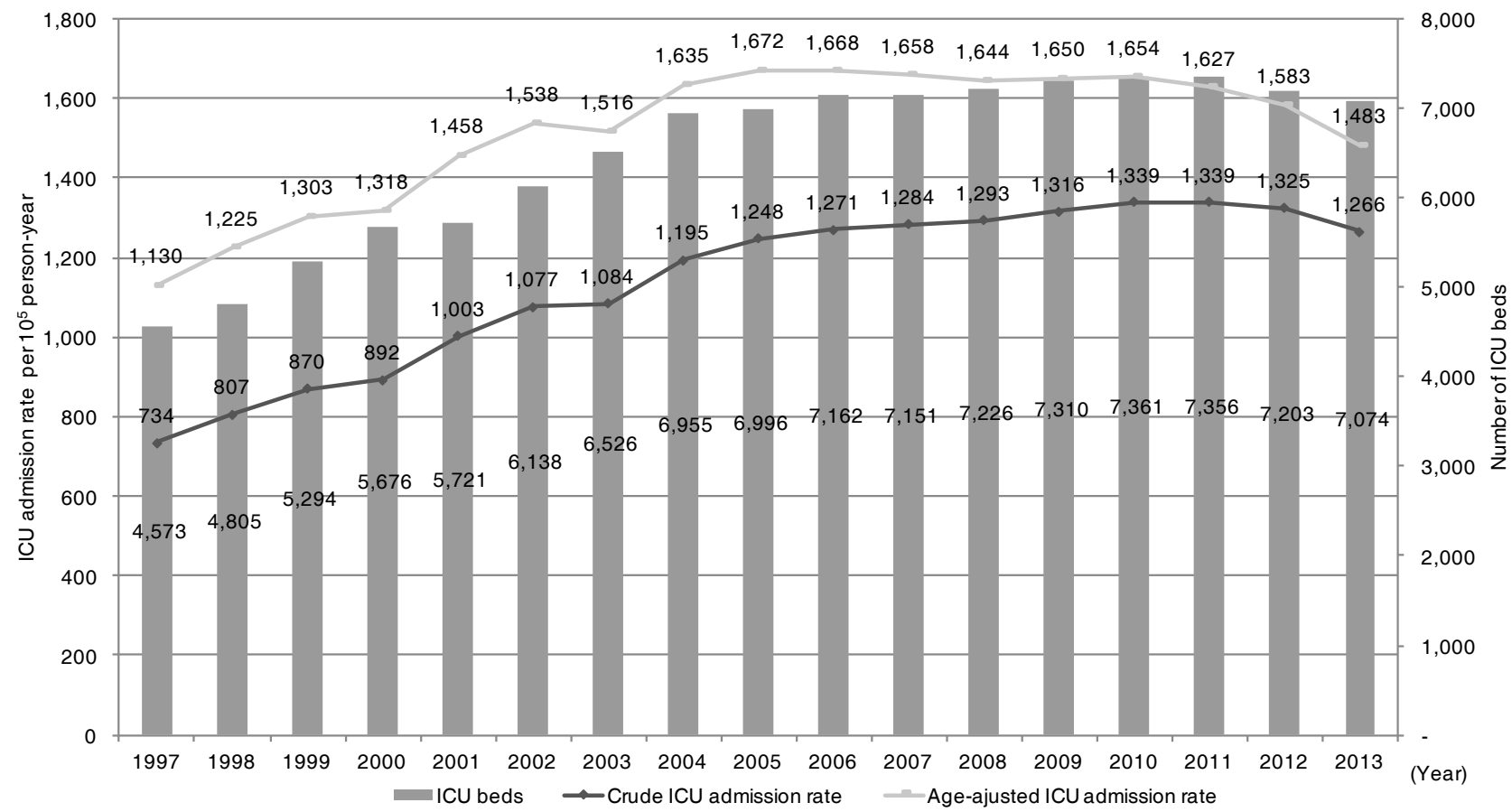

Figure 1 Annual intensive care unit (ICU) crude and age-adjusted admission rate per 100,000 populations in Taiwan, 1997-2013.

Table 2 Annual admission rate of different age group and trend analysis

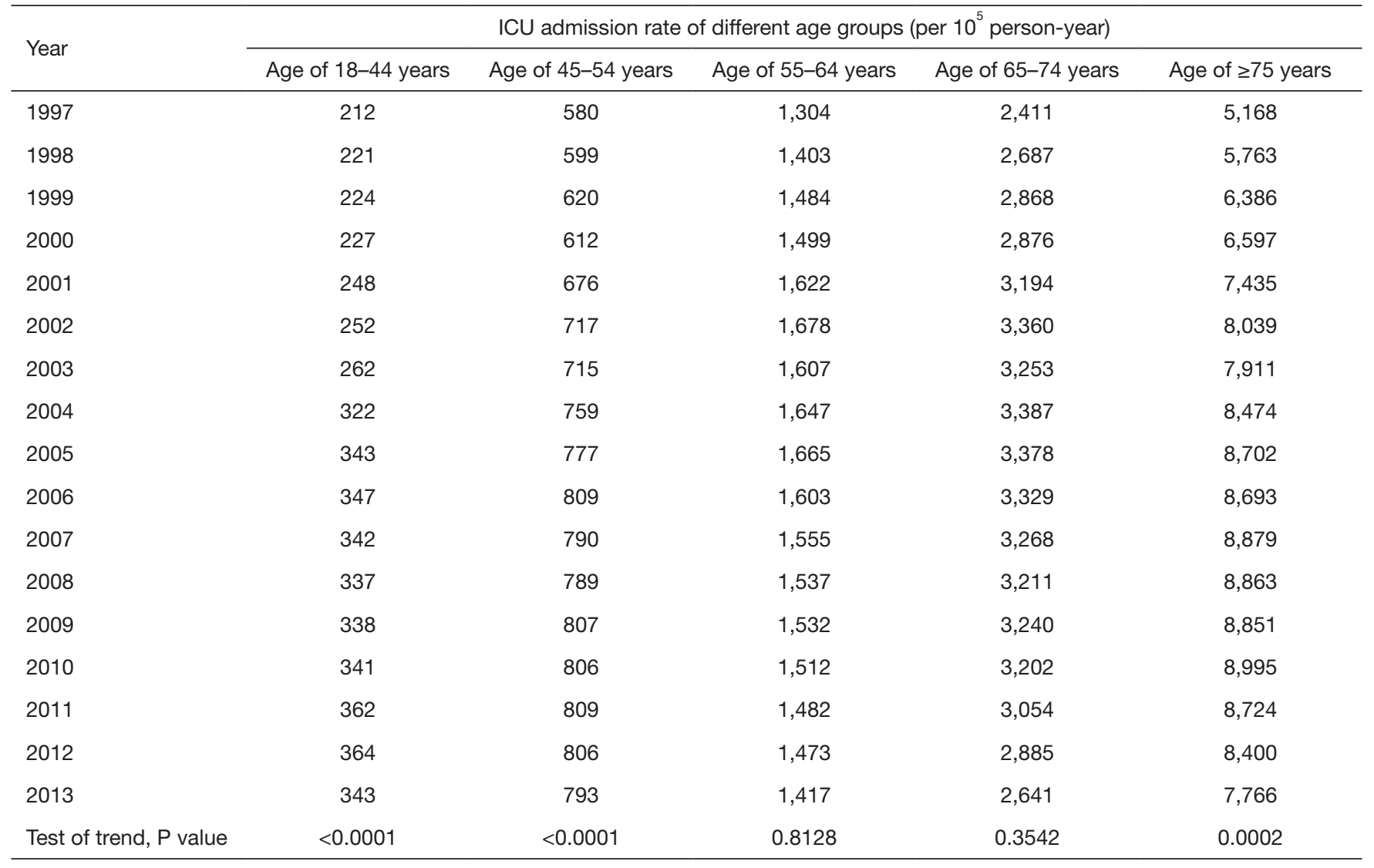




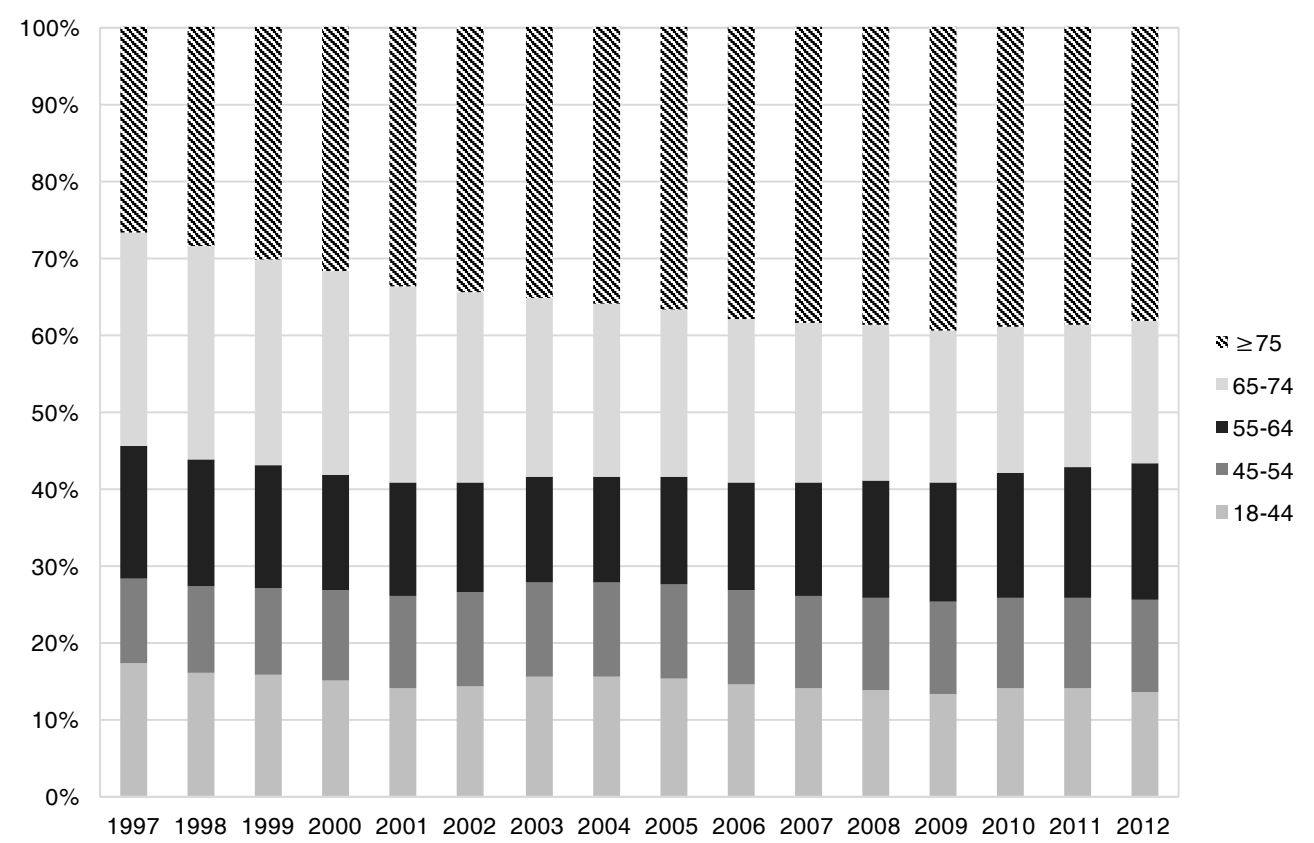

Figure 2 Annual age distribution of ICU admissions and general populations in Taiwan, 1997-2013. ICU, intensive care unit.

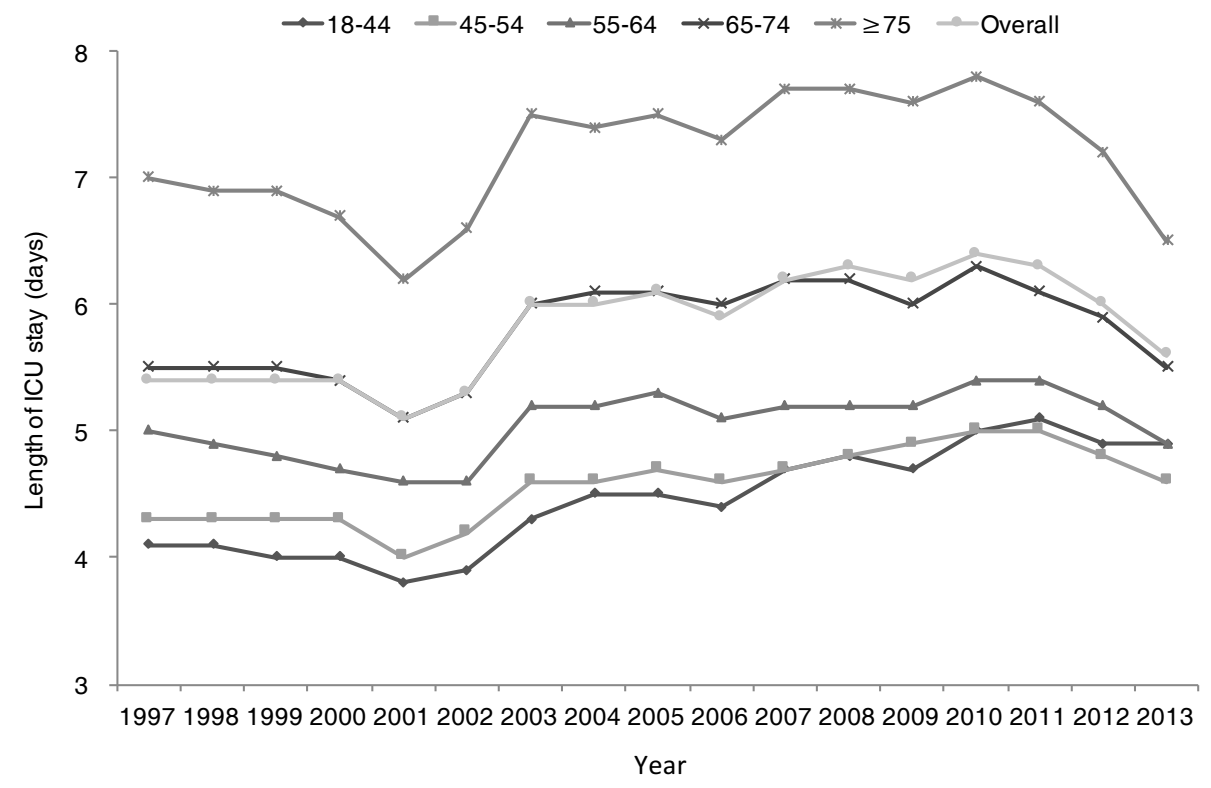

Figure 3 Length of ICU stays by age group in Taiwan, 1997-2013. ICU, intensive care unit.

period of this study, Taiwan was aggressively attempting to reduce long term care and result in inappropriate hospital uses for chronic patients in acute care hospitals (25). This could have contributed to increasing burden on short-term acute care facilities, including ICU admission. However, in 2009, NHI expands to include subacute care and chronic care (26), and thus some patients were shifted from ICU to long-term care facility.

In this study, the mortality declined with time. During these seventeen years, several important medical technologies and critical care measures were developed to 
$(\mathrm{N})$

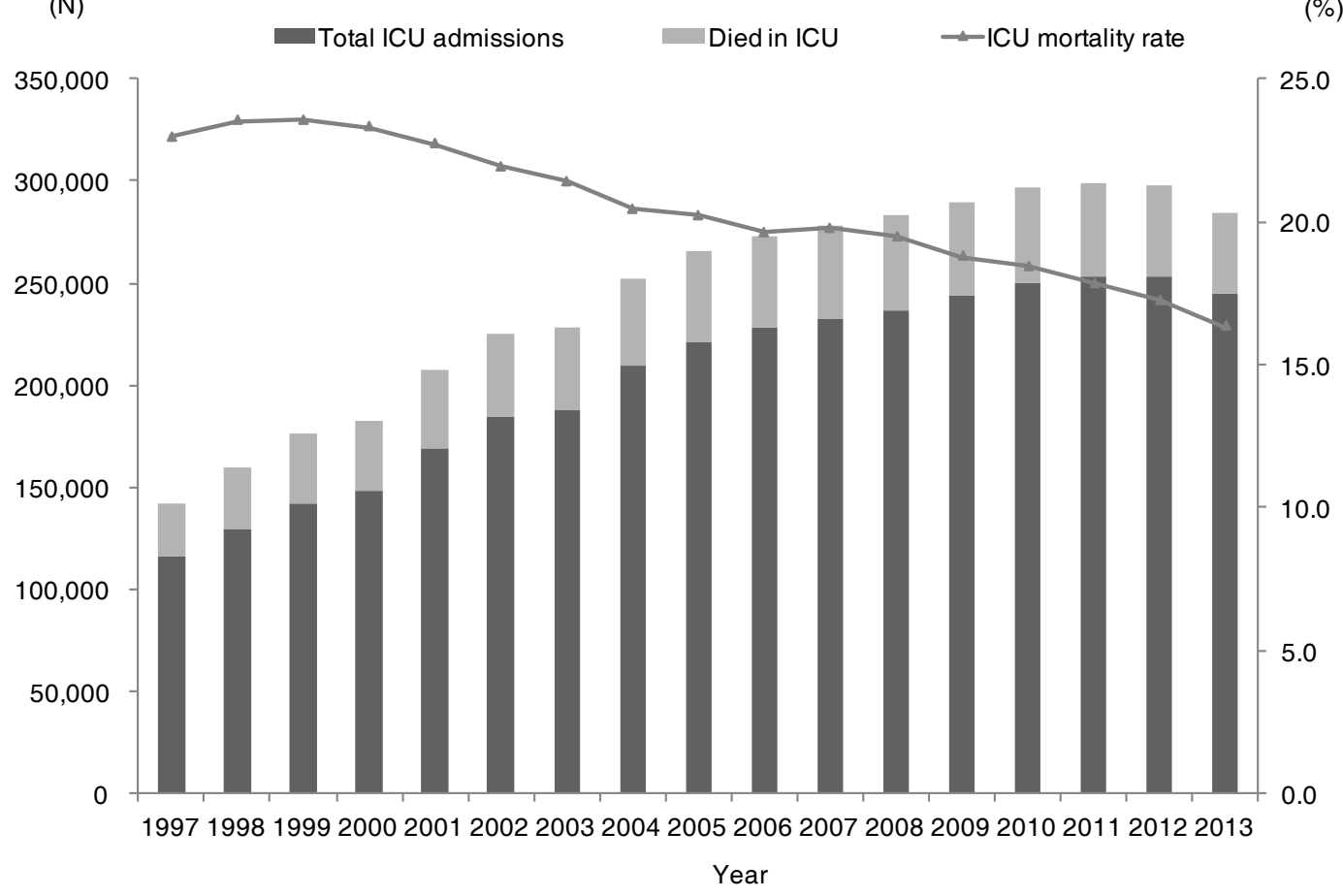

Figure 4 Number of ICU deaths, and ICU mortality rates, in Taiwan, 1997-2013. ICU, intensive care unit.

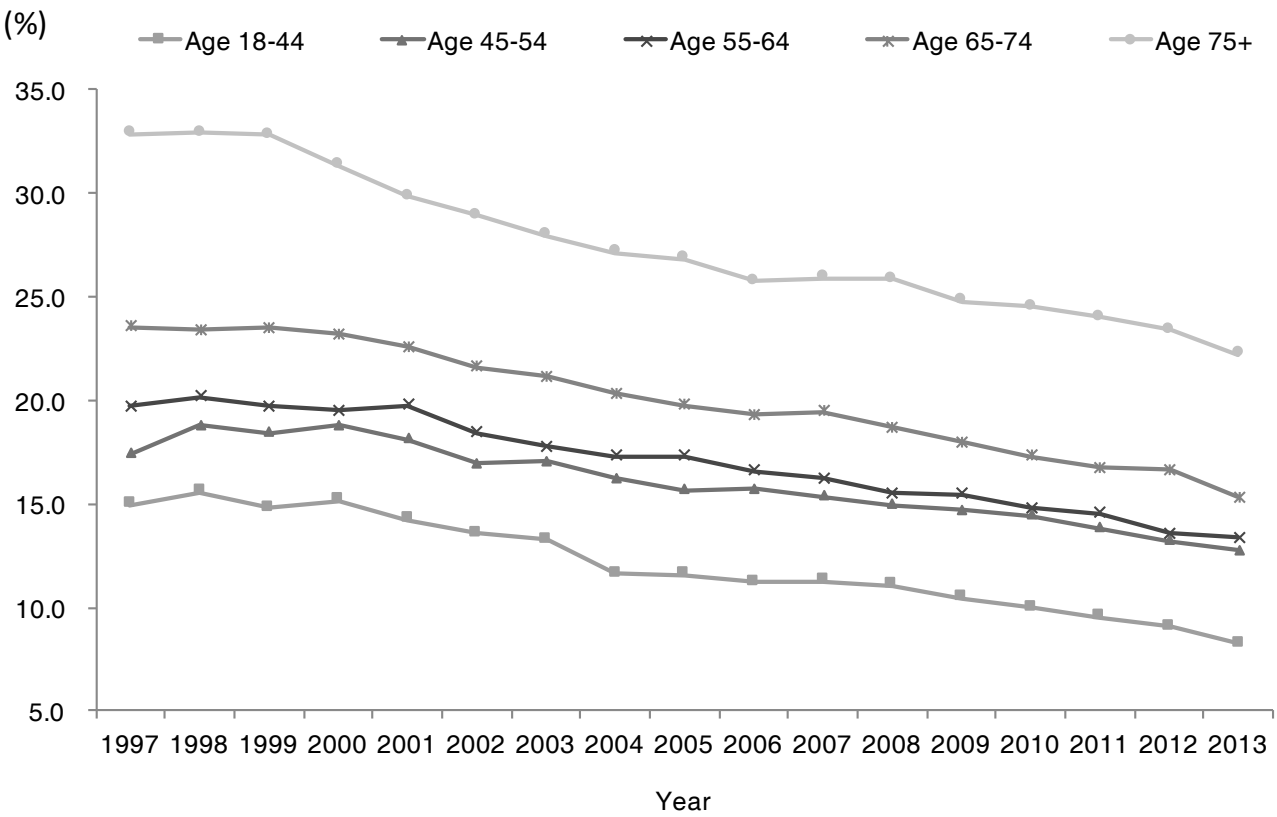

Figure 5 ICU mortality by age group in Taiwan, 1997-2013. ICU, intensive care unit. 
improve the outcomes of critically ill patients and the quality of critical care. For example, Amato et al. (27) reported that protective-ventilation strategy had reduced 28-day mortality in patients with acute respiratory distress syndrome, for the past eighteen years, this strategy has become a mainstay of ARDS treatment (28). For another common clinical disease-sepsis in ICU, several international organizations enrolling critical care and infectious disease experts initially developed evidence-based management guidelines-Surviving Sepsis Campaign guidelines (29) in 2004 and updated the recommendation with time in 2008 and $2012(30,31)$. These guidelines soon became standard management for severe sepsis and septic shock in the ICU, and their efficacy for improving outcomes in patients with sepsis and septic shock has been verified (32). Additionally, key elements of the guidelines were identified and organized into "bundles" of care (e.g., a ventilator bundle, central line-associated bloodstream infection bundle, and catheterassociated urinary tract infection bundle) were developed to prevent common complications in the ICU during this period. In 2009, Taiwan began accrediting the quantity and the quality of intensivists, critical care nurses, and equipment in the ICU to monitor the quality of in-hospital critical care given to patients. These measures might explain our findings of better outcomes in ICU patients.

In this study, we found that the ICU admission rate in Taiwan was higher than in the UK (216 per 100,000 population), Canada [389], France [426], and the Netherlands [466], but lower than in Germany [2,353] in 2005 (12). Additionally, our recent study showed that the number of ICU beds as well as the hospital beds in Taiwan has significantly increased at the same time (27). The total ICU beds increased from 4,573 in 1973 to 7,074 in 2013 and the ratio of ICU beds per 100,000 populations increased from 21.0 in 1997 to 30.3 in 2013, too (33). This ratio in Taiwan is similar as US (20 per 100,000 population), but much higher than Australia, France, Netherlands, Spain, Sweden and UK (all of them less than 10 per 100,000 population) (14). In addition, the number of ICU beds per 100 hospital beds ranged from $3.8 \%$ to $4.9 \%$ in Taiwan (33), which was similar to Germany (4.1\%), and Belgium (14). The ICU occupancy rate also increased from $66.5 \%$ to $72.1 \%$ during the same period (33). Therefore, all of our findings reflect the rapid expansion and high availability of critical care under the NHI system in Taiwan.

The overall ICU mortality in our study was consistent with the findings of North American, European, Australian, and New Zealand studies on unselected patients
$(14,19-21,34,35)$. We also found that ICU mortality was significantly higher in the elderly than in young adults, but not significantly different between genders. Like these other studies, however, we obtained only the raw mortality rate in a heterogeneous population, and mortality is affected by many factors, illness severity, case mix, hospital discharge policies, the hospital setting, and the hospital's administrative policies $(19,36,37)$.

Our study has some limitations. First, because the NHIRD does not provide specific types of clinical data, we were unable to study the disease severity such as SOFA and APACHE II scores, ICU specialty, cause of death and indications that a life-support device was required. Second, although we can obtain the diagnosis according to ICD9-CM code, we cannot sure which one diagnosis is the primary diagnosis for ICU admission. Therefore, we cannot evaluate this issue. Third, because we did not have data on critical care service before 1997, we cannot know the effect of NHI on intensive care. However, this study could provide useful information regarding the uses of ICU for Taiwan's adults. Additional investigations of the causes and consequences of these trends are required.

\section{Conclusions}

Using national population-based data, we found a significant increase in adult ICU admissions between 1997 and 2013, especially for the elderly, but a significant decline in mortality.

\section{Acknowledgements}

None.

\section{Footnote}

Conflicts of Interest: The authors have no conflicts of interest to declare.

Ethical Statement: The Chi Mei Medical Center Institutional Review Board approved the study and specifically waived informed consent (IRB NO: 10512-E01).

\section{References}

1. Halpern NA, Goldman DA, Tan KS, et al. Trends in critical care beds and use among population groups and medicare and medicaid beneficiaries in the United States: 
2000-2010. Crit Care Med 2016;44:1490-9.

2. Rabindranath K, Adams J, Macleod AM, et al. Intermittent versus continuous renal replacement therapy for acute renal failure in adults. Cochrane Database Syst Rev 2007;3:CD003773.

3. Tonelli M, Manns B, Feller-Kopman D. Acute renal failure in the intensive care unit: a systematic review of the impact of dialytic modality on mortality and renal recovery. Am J Kidney Dis 2002;40:875-85.

4. Acute Respiratory Distress Syndrome Network, Brower RG, Matthay MA, et al. Ventilation with lower tidal volumes as compared with traditional tidal volumes for acute lung injury and the acute respiratory distress syndrome. N Engl J Med 2000;342:1301-8.

5. Wan YD, Sun TW, Kan QC, et al. The effects of intraaortic balloon pumps on mortality in patients undergoing high-risk coronary revascularization: a meta-analysis of randomized controlled trials of coronary artery bypass grafting and stenting era. PLoS One 2016;11:e0147291.

6. Afessa B, Keegan MT, Hubmayr RD, et al. Evaluating the performance of an institution using an intensive care unit benchmark. Mayo Clin Proc 2005;80:174-80.

7. Knaus WA, Wagner DP, Zimmerman JE, et al. Variations in mortality and length of stay in intensive care units. Ann Intern Med 1993;118:753-61.

8. Moran JL, Solomon PJ. Mortality and other event rates: what do they tell us about performance? Crit Care Resusc 2003;5:292-304.

9. Thomas JW, Guire KE, Horvat GG. Is patient length of stay related to quality of care? Hosp Health Serv Adm 1997;42:489-507.

10. Halpern NA, Pastores SM. Critical care medicine in the United States 2000-2005: an analysis of bed numbers, occupancy rates, payer mix, and costs. Crit Care Med 2010;38:65-71.

11. Halpern NA, Pastores SM, Greenstein RJ. Critical care medicine in the United States 1985-2000: an analysis of bed numbers, use, and costs. Crit Care Med 2004;32:1254-9.

12. Wunsch H, Angus DC, Harrison DA et al. Variation in critical care services across North America and Western Europe. Crit Care Med 2008;36:2787-93.

13. Wunsch H, Wagner J, Herlim M, et al. ICU occupancy and mechanical ventilator use in the United States. Crit Care Med 2013;41:2712-9.

14. Adhikari NK, Fowler RA, Bhagwanjee S, et al. Critical care and the global burden of critical illness in adults. Lancet 2010;376:1339-46.
15. Woods AW, MacKirdy FN, Livingston BM, et al. Evaluation of predicted and actual length of stay in 22 Scottish intensive care units using the APACHE III system. Acute Physiology and Chronic Health Evaluation. Anaesthesia 2000;5 5:1058-65.

16. Cheng KC, Lu CL, Chung YC, et al. ICU service in Taiwan. J Intensive Care 2014;2:8.

17. Yoshiya I, Baik SW. Critical care in Japan and Korea. The market of excellence. Crit Care Clin 1997;13:267-85.

18. Marik PE, Hedman L. What's in a day? Determining intensive care unit length of stay. Crit Care Med 2000;28:2090-3.

19. Moran JL, Bristow P, Solomon PJ, et al. Mortality and length-of-stay outcomes, 1993-2003, in the binational Australian and New Zealand intensive care adult patient database. Crit Care Med 2008;36:46-61.

20. Cheng SH, Chiang TL. The effect of universal health insurance on health care utilization in Taiwan. Results from a natural experiment. JAMA 1997;278:89-93.

21. Cheng SH, Jan IS, Liu PC. The soaring mechanic ventilator utilization under a universal health insurance in Taiwan. Health Policy 2008;86:288-94.

22. Wen CP, Tsai SP, Chung WS. A 10-year experience with universal health insurance in Taiwan: measuring changes in health and health disparity. Ann Intern Med 2008;148:258-67.

23. Peng LN, Chen LK. Post-acute care for older patients: the emerging needs in Asia. J Gerontol Geriatric Res 2012;1:e101.

24. Taiwan's health care system: The next 20 years. Brookings Institution. 1BC. Available online: https://www.brookings. edu/opinions/taiwans-health-care-system-the-next-20years/

25. Chiu HC, Lee LJ, Hsieh HM, et al. Inappropriate hospital utilization for long-stay patients in southern Taiwan. Kaohsiung J Med Sci 2003;19:225-32.

26. National Health Insurance to include sub-acute care. 2009. Available online: http://taiwantoday.tw/news. php? unit $=10,23,45,10 \&$ post $=15380$

27. Amato MB, Barbas CS, Medeiros DM, et al. Effect of a protective-ventilation strategy on mortality in the acute respiratory distress syndrome. N Engl J Med 1998;338:347-54.

28. Serpa Neto A, Cardoso SO, Manetta JA, et al. Association between use of lung-protective ventilation with lower tidal volumes and clinical outcomes among patients without acute respiratory distress syndrome: a meta-analysis. JAMA 2012;308:1651-9. 
29. Dellinger RP, Carlet JM, Masur H, et al. Surviving Sepsis Campaign guidelines for management of severe sepsis and septic shock. Crit Care Med 2004;32:858-73. Erratum in: Crit Care Med 2004;32:2169-70; Crit Care Med 2004;32:1448. Dosage error in article text.

30. Dellinger RP, Levy MM, Carlet JM, et al. Surviving Sepsis Campaign: international guidelines for management of severe sepsis and septic shock: 2008. Crit Care Med 2008;36:296-327.

31. Dellinger RP, Levy MM, Rhodes A, et al. Surviving sepsis campaign: international guidelines for management of severe sepsis and septic shock: 2012. Crit Care Med 2013;41:580-637.

32. Levy MM, Dellinger RP, Townsend SR, et al. The Surviving Sepsis Campaign: results of an international guideline-based performance improvement program targeting severe sepsis. Intensive Care Med 2010;36:222-31.

33. Lai CC, Ho CH, Chang CL, et al. Availability of critical care service in Taiwan under National Health Insurance.

Cite this article as: Lai CC, Ho CH, Chang CL, Chen CM, Chiang SR, Chao CM, Wang JJ, Cheng KC. Critical care medicine in Taiwan from 1997 to 2013 under National Health Insurance. J Thorac Dis 2018;10(8):4957-4965. doi: 10.21037/ jtd.2018.07.131
Br J Anaesth 2017;119:335-7.

34. Metnitz PG, Moreno RP, Almeida E, et al. SAPS 3--From evaluation of the patient to evaluation of the intensive care unit. Part 1: Objectives, methods and cohort description. Intensive Care Med 2005;31:1336-44.

35. Harrison DA, Parry GJ, Carpenter JR, et al. A new risk prediction model for critical care: the Intensive Care National Audit \& Research Centre (ICNARC) model. Crit Care Med 2007;35:1091-8.

36. Bastos PG, Knaus WA, Zimmerman JE, et al. The importance of technology for achieving superior outcomes from intensive care. Brazil APACHE III Study Group. Intensive Care Med 1996;22:664-9.

37. Sirio CA, Shepardson LB, Rotondi AJ, et al. Communitywide assessment of intensive care outcomes using a physiologically based prognostic measure: implications for critical care delivery from Cleveland Health Quality Choice. Chest 1999;115:793-801. 